\title{
PERANCANGAN APLIKASI EDUKASI PENGENALAN ALAT MUSIK TRADISIONAL JAWA DI INDONESIA BERBASIS ANDROID
}

\author{
Diki Wahyu Mardian ${ }^{1}$, Didik Wiguna ${ }^{2}$, Bayu Jaya Tama ${ }^{3}$ \\ Program Studi Teknik Informatika, Fakultas Teknik dan Ilmu Komputer, \\ Universitas Indraprasta PGRI \\ Jalan Raya Tengah No 80, Kelurahan Gedong, Pasar Rebo, Jakarta Timur \\ mardiandiki14@gmail.com¹, didik.wiguna@gmail.com², baja134@gmail.com³
}

\begin{abstract}
Abstrak
Perkembangan teknologi telah membawa banyak perubahan dalam berbagai aspek kehidupan manusia. Seni merupakan sebuah keahlian dalam membuat suatu karya yang bernilai meliputi berbagai keindahan, fungsi, bentuk dan maknanya. Seiring dengan perkembangan kebudayaan manusia, kesenian sebagai produk budaya juga terus berkembang sesuai dengan masanya, seni mempunyai nilai tersendiri yang membuat karya ini bernilai mahal harganya. Pada era saat ini sangat jarang orang yang mengenal dan mampu memainkan alat musik tradisional tersebut. Sudah banyak media yang memuat informasi tentang alat musik tradisional tersebut. Mengenai rumusan masalah yaitu untuk merancang aplikasi yang sudah terkomputerisasi, unik dan terkonsep beda dari media lainnya, mengembangkan penerapan alat musik tradisional Jawa di Indonesia dan menambah daya tarik minat masyarakat. Hasil dari aplikasi nama-nama alat musik tradisional ini adalah untuk memberikan wawasan yang luas terhadap musik tradisional Jawa ini pada masyarakat, dan aplikasi yang telah berbasis Android. Metode yang digunakan peneliti dalam melakukan pengembangan aplikasi adalah metode Grounded Research. Dimana dalam membangun sistem ini digunakan alat bantu aplikasi edukasi pengenalan alat musik tradisional jawa di Indonesia yaitu Flowchart.
\end{abstract}

Kata Kunci: Android, Kebudayaan, Flowchart, Edukasi

\begin{abstract}
The development of technology has brought many changes in various aspects of human life. Art is a skill in making a work that is valuable covering various beauty, function, form and meaning. Along with the development of human culture, art as a cultural product also continues to grow in accordance with its time, art has its own value that makes this work worth a lot. In this era, it is very rare for people to know and be able to play traditional musical instruments. There are many media that contain information about traditional musical instruments. Regarding the formulation of the problem is to design applications that have been computerized, unique and conceptualized different from other media, develop the application of traditional Javanese musical instruments in Indonesia and add to the appeal of public interest. The result of the application of the names of these traditional musical instruments is to provide a broad insight into this traditional Javanese music to the community, and the application that has been based on Android. The method that the reseachers uses in performing application development is the Grounded Research method. Where in building this system used educational application tools introduction of traditional Javanese musical instruments in Indonesia, namely Flowchart.
\end{abstract}

Keywords: Android, Culture, Flowchart

\section{PENDAHULUAN}

(Nazruddin Safaat H, 2012) menjelaskan bahwa "aplikasi adalah satu unit perangkat lunak yang dibuat untuk melayani kebutuhan akan beberapa aktivitas seperti sistem penjaga, game, pelayanan masyarakat, periklanan atau semua proses yang dilakukan oleh manusia". Aplikasi pada umumnya digunakan untuk mengontrol perangkat keras (yang sering disebut sebagai device driver), melakukan proses perhitungan, dan berinteraksi dengan aplikasi yang lebih mendasar lainnya (seperti sistem operasi, dan bahasa pemrograman). Setiap daerah memiliki warisan budaya yang berbeda-beda dari nenek moyangnya seperti adat tradisional, baju tradisional dan kesenian musik 
tradisional. (Tiara Windy, 2015)Salah satu contoh warisan budaya kesenian musik tradisional adalah gamelan Jawa, dan alat musik daerah Jawa lainnya.

Sampai saat ini masih sedikit tentang media yang mengandung informasi mengenai alat musik tradisional tersebut. Hal ini harus dikembangkan, karena akan memudarkan rasa tingkat kepedulian masyarakat tentang informasi budaya bangsa Indonesia itu sendiri khususnya budaya Jawa yaitu tentang alat musik tradisional tersebut. Oleh karena itu, perlu penerapan yang baik adalah dengan merancang metode komputerisasi dengan media yang tepat yang mampu memberi kemudahan pada masyarakat, dan sederhana serta mudah dipahami dalam mencari media informasi tentang alat musik tradisional Jawa di Indonesia (Pramana, 2012).

(Safaat N, 2014) Android adalah sistem operasi untuk perangkat mobile berbasis linux yang mencakup sistem operasi, 12 middleware, dan aplikasi. Android menyediakan platform yang terbuka bagi para pengembangnya untuk menciptakan aplikasi mereka. Android merupakan sistem operasi untuk perangkat mobile berbasis linux yang mencakup sistem operasi, middleware dan aplikasi. Android menyediakan platform terbuka bagi para pengembang untuk menciptakan aplikasi itu sendiri yang digunakan oleh bermacam piranti bergerak. Dalam hal ini aplikasi dirancang dengan sistem android sebagai bahan dalam penelitian. (Subagyo, 2010) musik tradisional nusantara adalah musik yang berkembang diseluruh kepulauan dan merupakan kebiasaan turun-menurun yang masih dijalankan dalam masyarakat. Musik tradisional merupakan sebuah alat yang asal muasal atau sebagai ciri khas dari daerah itu sendiri yang mengandung unsur keunikan dan kegunaan nya yang bermanfaat bagi masyarakat tersebut. Hasil penelitian ini sebagai alat untuk sarana informasi khususnya alat musik tradisional Jawa di Indonesia.

\section{PENELITIAN RELEVAN}

Dalam rangka melakukan penelitian tentang aplikasi pengenalan, maka penulis mencari sumber terlebih dahulu yang berhubungan dengan aplikasi pengenalan yang akan penulis lakukan. Salah satunya dari (Nur Afiat Umar, Ahmad S, 2015) dalam penelitiannya tentang Aplikasi Pembelajaran Dan Pengenalan Budaya Indonesia Berbasis Multimedia. Tujuan Penelitian ini adalah Membangun sebuah aplikasi berbasis multimedia dan pengenalan budaya yang interaktif untuk para siswa.

Penelitian selanjutnya oleh (Qosasih, 2015) dalam penelitiannya tentang Perancangan Aplikasi Pengenalan Huruf Arab Di Tk Nurul Farhah Menggunakan Java. Tujuan Penelitian ini adalah langkah sebuah pencapaian yang diharapkan dapat memberikan edukasi kepada anak-anak untuk mengenal huruf-huruf arab. Hal ini juga merupakan suatu tindakan untuk menumbuhkan karakter anak dan mendidik tentang keagamaan.

\section{METODE PENELITIAN}

Dalam desain penelitian menggunakan Grounded Research data merupakan sumber teori, dan teori tersebut grounded karena teori tersebut berdasarkan data (Nazir, 2011) Grounded Research adalah suatu metode penelitian yang mendasarkan diri kepada fakta dan menggunakan analisis perbandingan bertujuan untuk mengadakan generalisasi empiris, menerapkan konsep-konsep, membutuhkan teori, dan mengembangkan teori dimana pengumpulan data dan analisis data berjalan pada waktu bersamaan.

Teknik pengumpulan data mempelajari data dari internet dan buku-buku yang berkaitan dengan penelitian dalam menganalisis dan mendesain sebuah sistem dan perihal informasi tentang alat musik tersebut. Mempelajari sistem aplikasi edukasi yang serupa dengan aplikasi yang dibuat, dengan observasi, serta data akurat dari internet maupun secara langsung. Ruang lingkup Penelitian, Penulis mempelajari dan mengamati kegiatan yang terdapat pada industri terkait mengenai alat musik sebagai alat analisa serta keterkaitan antara subsistem satu dengan subsistem lainya.(Subhan, 2012) Penulis melakukan pengumpulan data dengan cara melihat dan mencatat data yang diperlukan dari alat musik gamelan tersebut. 


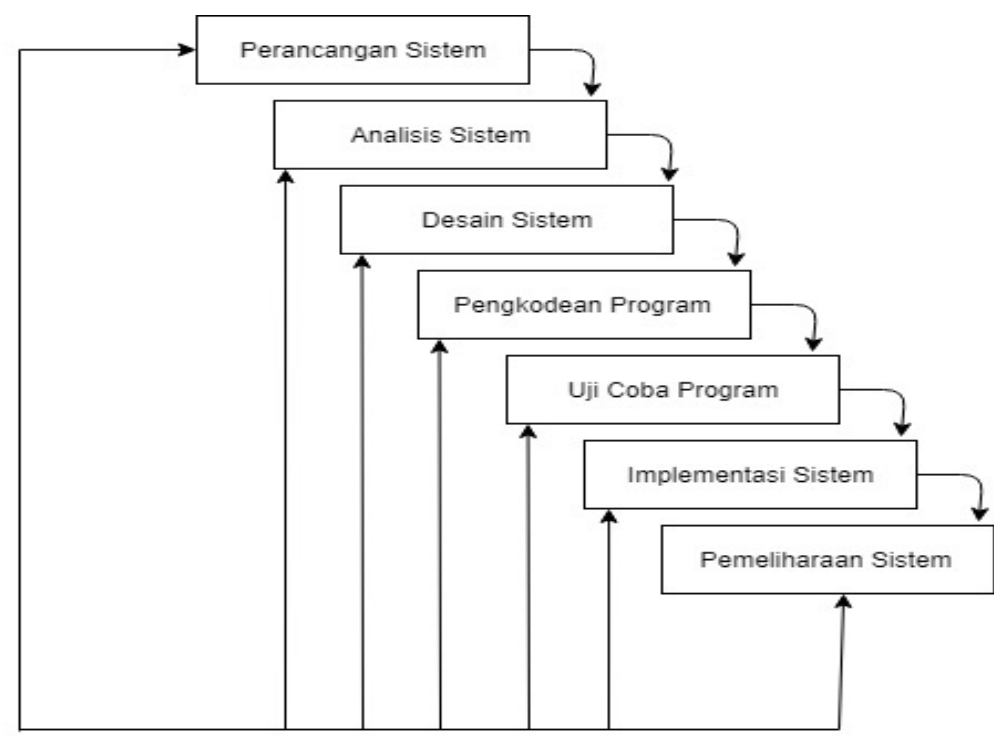

Gambar 1. Grounded Research

\section{HASIL DAN PEMBAHASAN}

(Krismiaji, 2015) "flowchart" merupakan teknik analistis yang digunakan untuk menjelaskan aspek-aspek sistem informasi secara jelas, tepat dan logis. Flowchart juga suatu diagram yang digunakan untuk mengilustrasikan sebuah struktur dalam kegiatan yang akan diproses untuk pencapaian sesuatu, atau membantu pembuat perangkat lunak menjelaskan perangkat lunak yang dibuat kepada orang lain.

Berikut ini adalah Flowchart Aplikasi Edukasi PengenalanAlat Musik Tradisional Jawa di Indonesia Berbasis Mobile Android:

\section{Flowchart Login}

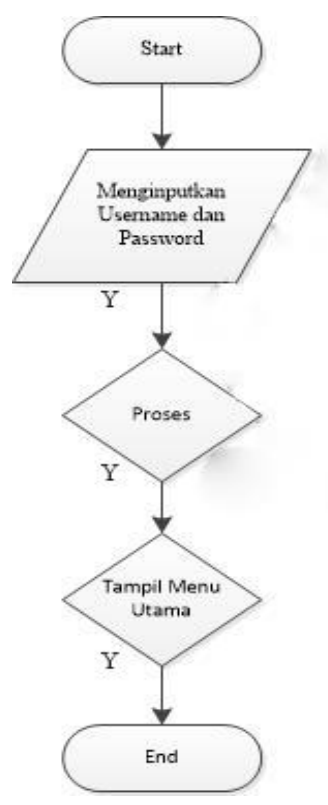

Gambar 2. Flowchart Login 
Jurnal Riset dan Aplikasi Mahasiswa Informatika (JRAMI)

Vol 이 № 03 Tahun 2022

e-ISSN : $2715-8756$

\section{Flowchart Menu Utama}

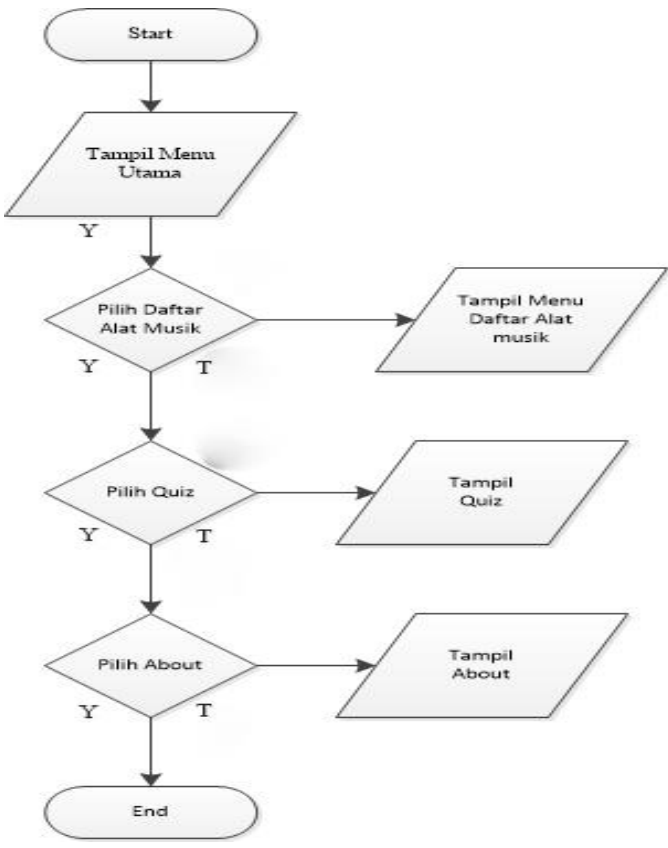

Gambar 3 Flowchart Menu Utama

\section{Flowhart Daftar Alat Musik}

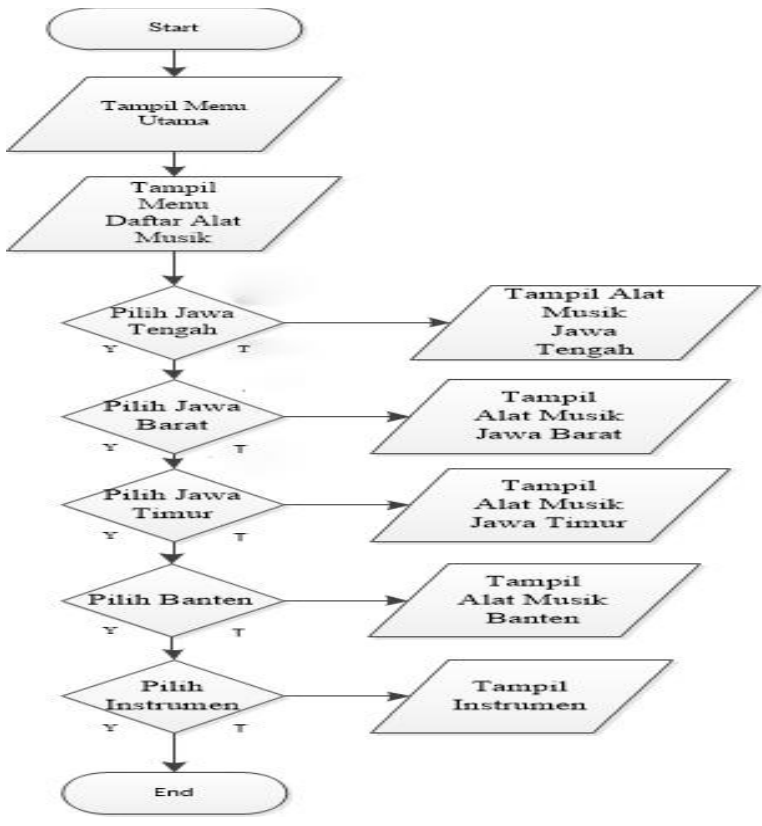

Gambar 4. Flowhart Daftar Alat Musik 
Jurnal Riset dan Aplikasi Mahasiswa Informatika (JRAMI)

Vol OI No Q3 Tahun 2022

e-ISSN : $2715-8756$

Flowchart Menu Quiz

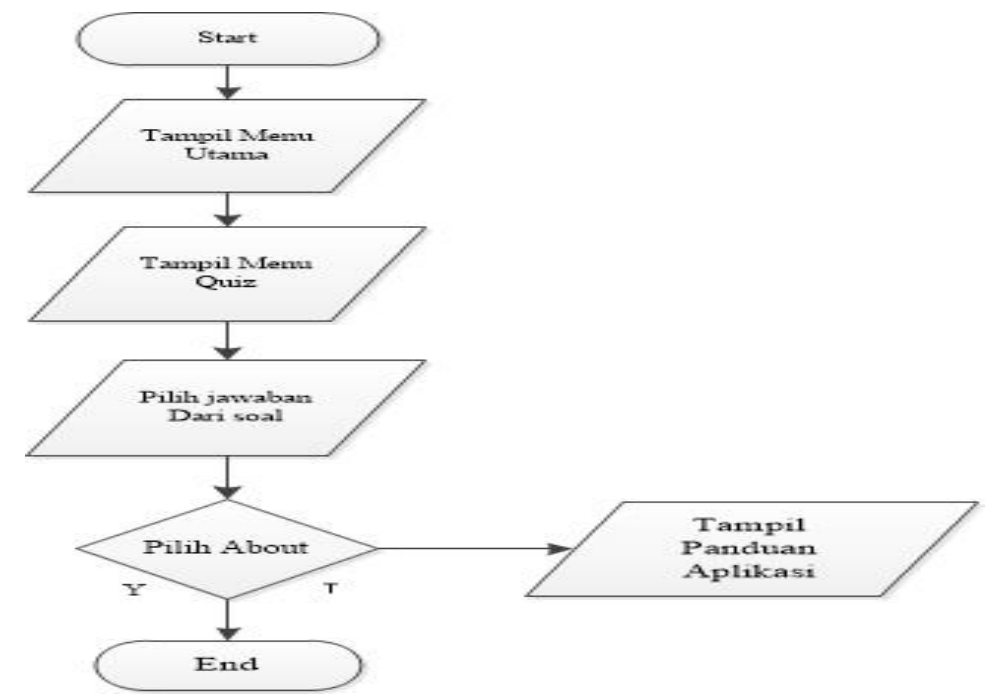

Gambar 5. Flowchart Menu Quiz

\section{Flowchart Menu Tentang}

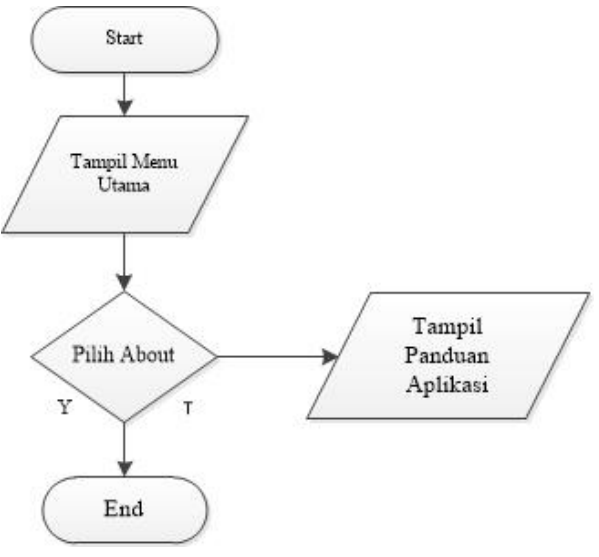

Gambar 6. Flowchart Menu Tentang

\section{Tampilan Layar}



Gambar 7. Tampilan Splash Screen

Tampilan Splash Screen menampilkan identitas atau ciri dari Aplikasi Edukasi Pengenalan Alat Musik Tradisional Jawa di Indonesia. 


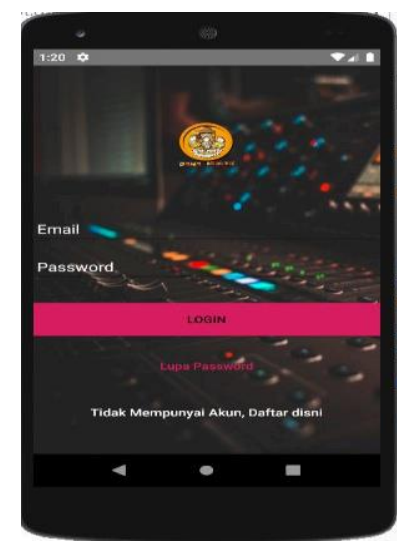

Gambar 8. Tampilan Menu Utama

Tampilan Login menampilkan tentang Aplikasi Edukasi Pengenalan Alat Musik Tradisional Jaw di Indonesia.

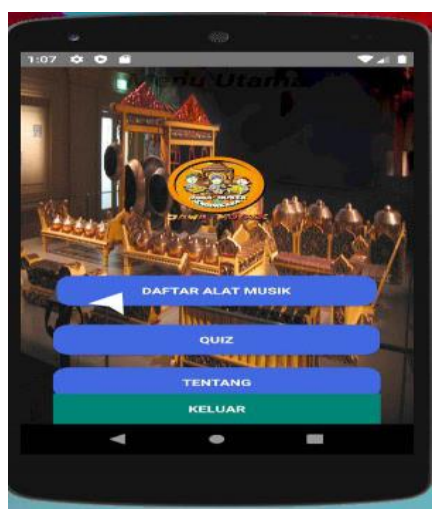

Gambar 9. Tampilan Menu Utama

Tampilan Menu Utama ini menampilkan menu-menu yang ada pada aplikasi ini. Pada menu utama terdapat menu daftar alat musik, quiz dan tentang.

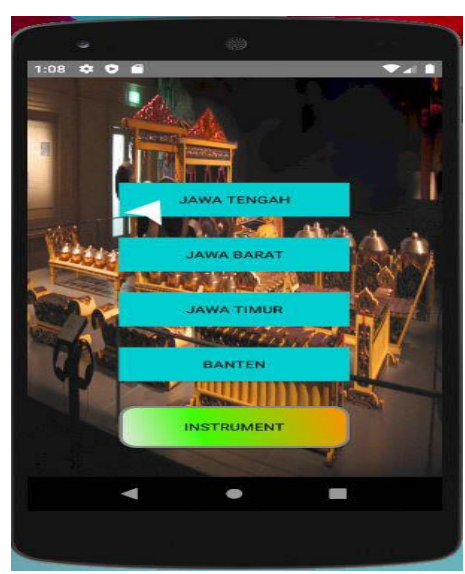

Gambar 10. Tampilan Menu Daftar Alat Musik

Tampilan menu daftar alat musik menampilkan berbagai menu dari setiap daerah Jawa Tengah, Jawa Timur, Jawa Barat, dan Banten. Di setiap menu ini terdapat alat musik yang khas dari daerah tersebut. 


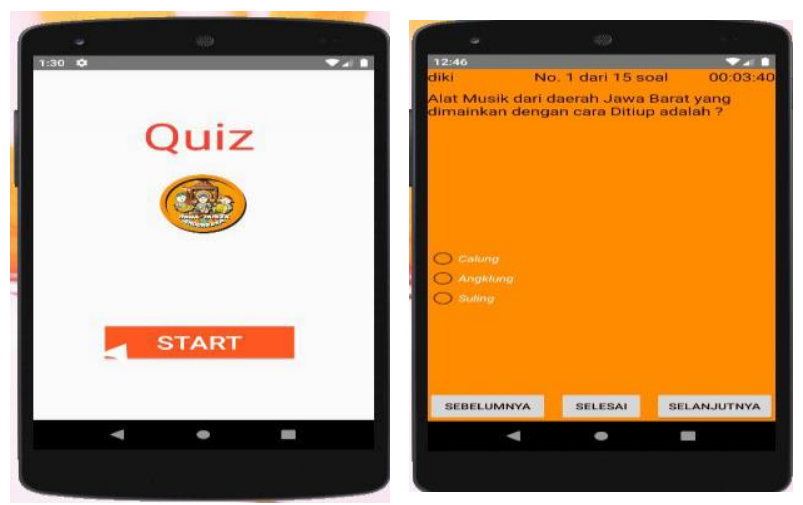

Gambar 11. Tampilan Menu Quiz

Tampilan menu kuis menampilkan soal-soal untuk menguji kemampuan edukasi pengenalan alat musik tradisional Jawa di Indonesia yang telah anda pelajari..


Gambar 12. Tampilan Menu Tentang

Tampilan tentang menampilkan informasi dari profil dari penulis informasi tersebut.

\section{SIMPULAN}

Aplikasi ini memudahkan penggunanya dalam mengetahui dan mengenal tentang alat musik tradisional yang hanya terdapat dari daerah khusus Jawa Tengah, Jawa Timur, Jawa Barat, dan Banten. Dengan adanya aplikasi tersebut mempelajari alat musik tradisional Indonesia khususnya pulau Jawa menjadi lebih mudah dengan menggunakan smartphone Android, karena penggunaan smartphone saat ini tidak hanya digunakan sebagai media komunikasi, melainkan juga sebagai media informasi.

\section{DAFTAR PUSTAKA}

Krismiaji. (2015). Sistem Informasi Akuntansi. UPPSTIM YKPN.

Nazir, M. (2011). Metode Penelitian. Penerbit Ghalia Indonesia.

Nazruddin Safaat H. (2012). Perangkat Lunak Aplikasi. STIKOM Dinamika Bangsa.

Nur Afiat Umar, Ahmad S, H. N. (2015). Aplikasi Pembelajaran Dan Pengenalan Budaya Indonesia Berbasis Multimedia. Jurnal Pembelajaran, 3(1)(2442-5826). https://www.google.co.id/openlibrary

Pramana, H. W. (2012). Aplikasi Inventory Berbasis Access 2003. PT. Elek Media Komputindo.

Qosasih, S. M. (2015). Perancangan Aplikasi Pengenalan Huruf Arab Di Tk Nurul Farhah Menggunakan Java. Universitas Indraprasta PGRI.

Safaat N. (2014). Android Pemrograman Aplikasi Mobile Smartphone Dari Tablet PC Berbasis Android. Informatika.

Subagyo, W. P. dan F. (2010). Terampil Bermusik. Pusat Perbukuan Pendidikan Nasional.

Subhan, M. (2012). Analisa Perancangan Sistem. Lentera Ilmu Cendikia.

Tiara Windy, L. (2015). Aplikasi Budaya Nusantara Berbasis Android Menggunakan Frame Work Phonegap. Universitas Gunadarma. 